\title{
LA INVESTIGACION HISTORICO-COMPARATIVA DEL CONSTITUCIONALISMO LATINOAMERICANO Y EL CASO URUGUAYO
}

\author{
José Miguel Busquets* \\ Oscar Sarlo ${ }^{* *}$
}

\begin{abstract}
Resumen: El presente trabajo comienza caracterizando como objeto, al constitucionalismo latinoamericano y presentando las periodizaciones realizadas sobre el mismo por los constitucionalistas Gros Espiell y Roberto Gargarella. El artículo tiene como objetivo desarrollar una revisión de los dos programas más relevantes de investigación contemporánea sobre el constitucionalismo latinoamericano, los programas de Negretto y de Gargarella. Posteriormente, hace un análisis comparado de dos casos de reforma constitucional en Uruguay, 1967 y 1997. Finalmente, presenta una agenda de investigación sobre el constitucionalismo.
\end{abstract}

Palabras claves: constitucionalismo; reforma constitucional; análisis comparado

\section{THE COMPARATIVE HISTORICAL RESEARCH OF LATIN AMERICAN CONSTITUTIONALISM AND THE URUGUAYAN CASE.}

\begin{abstract}
The present work begins by characterizing Latin American constitutionalism as an object and presenting the periodizations made on it by the constitutionalists Gros Espiell and Roberto Gargarella. The article aims to develop a review of the two most relevant contemporary research programs on Latin American constitutionalism, the Negretto and Gargarella programs. Later, he makes a comparative analysis of two cases of constitutional reform in Uruguay, 1967 and 1997. Finally, he presents a research agenda on constitutionalism.
\end{abstract}

Keywords: constitutionalism; constitutional reform; comparative analysis;

* Doctor en Ciencia Política por la Universidad Candido Mendez, UCAM, Río de Janeiro (Brasil). Profesor Titular de Ciencia Política en la Facultad de Derecho (UdelaR), e investigador en régimen de Dedicación Total (CSIC). Investigador Nivel I, Sistema Nacional de Investigadores (ANII).

** Doctor en Derecho y Ciencias Sociales (título de grado). Profesor Titular de Filosofía y Teoría del Derecho en la Facultad de Derecho (UdelaR). Investigador en régimen de Dedicación Total (CSIC). Investigador Nivel II, Sistema Nacional de Investigadores (ANII). 


\section{INTRODUCCIÓN}

La comparación constitucional ha interesado desde hace siglos. Debemos a Aristóteles uno de los primeros ejercicios en tal sentido. ${ }^{1}$

En América Latina existe una tradición de estudios constitucionales comparados bastante relevantes desarrollados por profesores pertenecientes a la dogmática constitucional. En este campo quizás el liderazgo pueda reconocerse a los investigadores de la Universidad Nacional Autónoma de México que impulsó vastos programas de investigación comparatista, fundamentalmente a través de su Instituto de Investigaciones Jurídicas, convocando generalmente el concurso de diversos expertos latinoamericanos y europeos. 2

La apertura al comparatismo de la dogmática constitucional por si solo va requiriendo salir de la propia dogmática, en demanda de variables provenientes de otros campos que permitan comprender o explicar mejor la dinámica constitucional a través de una historia que se va haciendo cada vez más rica y compleja. En este sentido, baste recordar la opinión del constitucionalista uruguayo Gros Espiell, para quien "Es imposible comprender la histórica de Iberoamérica, sin estudiar el proceso constitucional y legislativo que siguió, en el Siglo XIX, a la Revolución y a la Independencia. De igual modo, no es posible captar el sentido y la naturaleza de la historia iberoamericana en el siglo XX y la situación actual, sin analizar los grandes cambios constitucionales producidos en el período posterior a la primera post guerra -

1 Aristóteles fue uno de los primeros en la historia registrada en hacer una distinción formal entre el derecho ordinario y el derecho constitucional, estableciendo ideas de constitución y constitucionalismo, y tratando de clasificar las diferentes formas de gobierno constitucional. En sus obras La Constitución de Atenas, Política y Ética de Nicómaco exploró diferentes constituciones de su época, incluyendo las de Atenas, Esparta y Cartago. Clasificó lo que él consideraba constituciones buenas y malas, y llegó a la conclusión de que la mejor constitución era un sistema mixto, incluyendo elementos monárquicos, aristocráticos y democráticos; ver: Cordeiro, José Luis, Constitutions around the World: A View from Latin America, IDE Discussion Paper. No. 164. 2008; Barnes, J. , The Cambridge Companion to Aristotle. Cambridge, UK: Cambridge University Press, 1995.

2 A título sólo enunciativo, mencionamos: Krüger, Herbert, et al., El constitucionalismo a mediados del siglo XIX, (2 vols.), México, UNAM, 1957; Pantoja Morán, D., La idea de soberanía en el constitucionalismo latinoamericano, México : UNAM, 1973; Valadés, Diego, La dictadura constitucional en América Latina, México, UNAM, 1974; AAVV, El Control constitucional de la política exterior en América Latina, México, UNAM, 1973; AAVV, El predominio del Poder Ejecutivo en Latinoamérica, México, UNAM, Instituto de Investigaciones Jurídicas, 1977; Fix-Zamudio,Héctor et al. Función del poder judicial en los sistemas constitucionales latinoamericanos, México, UNAM, Instituto de Investigaciones Jurídicas, 1977. de Castro Borges, Arthur et al., Evolución de la organización político-constitucional en América Latina (1950-1975), México, UNAM, Instituto de Investigaciones Jurídicas, 1978-1979; Gil Valdivia, Gerardo; Chavez Tapia, Jorge, Evolución de la organización Política-Constitucional en América Latina (1950-1975), México, Unam, 1979; Instituto de Investigaciones Jurídicas, El constitucionalismo en las postrimerías del siglo XX, México, D.F. : UNAM, 1988; Carbonell, Miguel; Carpizo, Jorge; Zovatto, Daniel; Tendencias del constitucionalismo en Iberoamérica, México, UNAM, 2009; von Bogdandy, Armin; Fix Fierro, Héctor; Morales Antoniazzi, Mariela; Ius constitutionale commune en América Latina rasgos, potencialidades y desafíos, México, D.F., UNAM, Instituto de Investigaciones Jurídicas, Instituto Max Planck de Derecho Público Comparado y Derecho Internacional, 2014.. 


\section{LA INVESTIGACION HISTORICO-COMPARATIVA DEL CONSTITUCIONALISMO LATINOAMERICANO Y EL CASO URUGUAYO}

muchas veces bajo la influencia de la evolución constitucional europea del momento-, en los años que siguieron al fin de la Segunda Guerra Mundial y en las últimas décadas, con la consideración del constitucionalismo africano y de los países descolonizados y la proyección de nuevos problemas y cuestiones, como por ejemplo, la protección internacional de los derechos humanos, la cuestión de las poblaciones indígenas, la aplicación interna del Derecho Internacional, la integración económica y la defensa del medio ambiente y el concepto actual de soberanía."

Por cierto, en el desarrollo del comparatismo constitucional no sólo existen intereses académicos; también han influído motivaciones de estrategia política internacional. En este sentido no debemos olvidar que la segunda guerra mundial desató un renovado interés por los estudios constitucionales comparados en el marco de la política panamericanista de los EEUU. ${ }^{3}$

Desde la década de los 70s ha tomado un nuevo impulso la comparación constitucional a nivel global impulsada desde medios académicos norteamericanos ${ }^{4}$, estimulado luego por movimientos constitucionales regionales, como en la Europa del Este en la era post-soviética, o las nuevas repúblicas africanas o asiáticas, y más recientemente por el movimiento constitucionalista en América Latina. ${ }^{5}$

En este último período de estudios comparatistas que arranca en los años 70, encontramos diversos programas, que expresan intereses, métodos y objetos muy diferentes. Pero la característica más destacable es que la acumulación y disponibilidad de una mayor información sobre las constituciones del mundo, así como una mayor acumulación de explicaciones teóricas, han permitido pasar de simples reportes descriptivos de las constituciones a pretensiones más explicativas en torno a ciertas funcionalidades de éstas.

De manera que en la actualidad es posible hablar de un campo de investigación que podemos denominar 'constitucionalismo', el cual tiene por objeto estudiar los procesos de

3 En este sentido son referentes las investigaciones desarrolladas por el constitucionalista alemán, naturalizado en los EEUU, Karl Loewenstein (1891 - 1973). Aparte de sus trabajos en el período de la II Guerra Mundial, sus conclusiones teóricas pueden verse en: Loewenstein, Karl, Teoría de la Constitución, Barcelona, Ariel, 1970.

4 Podemos considerar que tal movimiento se inicia con la monumental "Constitutions of the countries of the world: [a series of updated texts, constitutional chronologies and annotated bibliographies], de los profesores Albert P. Blaustein y Gisbert H. Flanz, serie publicada por la Editorial Dobbs Ferry N.Y., Oceana, a partir de 1971.

5 Las cabezas más visibles -pero no las únicas- de los estudios del constitucionalismo en América Latina son los trabajos de Roberto Gargarella y de Gabriel Negretto que hemos elegido como base para nuestro estudio. 
producción y cambio, y las formas y funciones de las constituciones en determinados contextos geográficos e históricos. ${ }^{6}$

Como contribución a ese movimiento de investigación del constitucionalismo latinoamericano nos proponemos testear en el caso uruguayo, algunas hipótesis de los más recientes y relevantes programas de investigación sobre las causas de las reformas constitucionales en América Latina.

Para ello, primero damos cuenta de algunos antecedentes referidos a la periodización del constitucionalismo latinoamericano, para luego examinar dos de los más relevantes programas de investigación sobre las reformas constitucionales en América Latina, para lo cual detallamos sus objetos, objetivos, diseños (problema, marco teórico, estrategia metodológica, variables), resultados y observaciones críticas.

Posteriormente, hacemos un cotejo empírico con el caso uruguayo, en dos instancias de cambios en el diseño constitucional, el remplazo de 1967 y la enmienda de 1997, previa anotación de algunas observaciones críticas a los programas de investigación.

Finalmente, hacemos consideraciones teóricas y empíricas, inventariando posibles nuevos caminos de investigación.

\section{SOBRE LA PERIODIZACIÓN DEL CONSTITUCIONALISMO LATINOAMERICANO.}

En el período conformativo de cualquier campo disciplinar, es frecuente que la descripción, clasificación y compararación sean las tareas preferidas. Ellos facilitan el manejo de gran cantidad de episodios o casos, ofreciendo las primeras interpretaciones y generalizaciones, que dan sentido a interpretaciones más complejas.

6 El término 'constitucionalismo' tiene en la literatura diversos sentidos: (a) la cultura de una sociedad en torno a la constitución; (b) en sentido político, una forma de gobierno que racionaliza el poder y busca garantizar a todos sus derechos mediante una constitución, y también la ideología partidaria de este sistema; (c) en sentido jurídico, refiere a un sistema normativo basado en la preeminencia de un texto constitucional; (d) en sentido social, refiere a la tendencia que busca limitar el poder de los gobernantes con la finalidad de proteger la autonomía individual; (e) una disciplina de conocimiento que tiene por objeto el estudio de la función y posición que ejercen las constituciones en las diferentes sociedades y sistemas políticos, así como la evolución histórica del texto constitucional en un determinado Estado. Nosotros adoptamos aquí este último concepto de 'constitucionalismo'. Para un tratamiento analítico más preciso, puede consultarse: Commanducci, Paolo, «Constitucionalismo»: problemas de definición y tipología, en: DOXA, Cuadernos de Filosofía del Derecho, 34 (2011), pp. 95-100. 


\section{LA INVESTIGACION HISTORICO-COMPARATIVA DEL CONSTITUCIONALISMO \\ LATINOAMERICANO Y EL CASO URUGUAYO}

El constitucionalismo latinoamericano no es una excepción. Como ya vimos existe una larga tradición de estudios comparativos descriptivos en sentido horizontal ${ }^{7}$. Pero también encontramos trabajos abarcativos del fenómeno constitucional latinoamericano que se proponen distinguir ciclos o fases en su desarrollo histórico (comparatismo vertical). Estos ejercicios son interesantes en la medida que -explícita o implícitamente- sus autores creen advertir causas o condiciones determinantes de ciertas homogeneidades regionales en tal proceso evolutivo, y por esa vía empiezan a vislumbrar hipótesis explicativas del movimiento constitucional.

Mencionaremos dos propuestas que, aún cuando elaboradas con herramientas diversas y con cierto desfasaje temporal entre sí, reflejan de manera interesante afinidades y divergencias que ayudan a delinear un fenómeno teorizable. Ellas son las de Héctor Gros Espiell y Roberto Gargarella.

\subsection{Ciclos del constitucionalismo iberoamericano según Gros Espiell. ${ }^{8}$}

Gros Espiell propone considerar seis ciclos ${ }^{9}$ en la evolución del constitucionalismo latinoamericano. El trabajo de este autor, reviste interés dado que para su periodización, rompe con los criterios de la dogmática tradicional, y utiliza criterios externos a ésta. En efecto, más allá de su formación en la dogmática constitucional, Gros basa su periodización en factores extra-dogmáticos, y en especial, en las grandes fases de la política internacional.

Primer ciclo: 1810-1850. Cubre desde la Independencia hasta mediados del siglo XIX. El constitucionalismo contribuye a la construcción de las identidades nacionales, y a la afirmación de la forma republicana de gobierno (salvo las excepciones de Brasil y la experiencia de Iturbide en México) pero sin referencia a la expresión democrática. Estas constituciones ignoraron las comunidades indígenas y los partidos políticos, proclaman el fin de la esclavitud, y las relaciones privadas continúan -salvo excepciones- bajo la legislación colonial. Se configura el modelo de del presidencialismo latinoamericano, por el cual "las mismas elites criollas, las

7 En efecto, los trabajos mencionados en la nota 2 responden fundamentalmente al propósito descriptivo de la comparación horizontal.

8 Gros Espiell (1926 - 2009) fue profesor de Derecho Constitucional y de Derecho Internacional Público uruguayo, ocupó distintos cargos políticos en el país (ministro de Estado en varias oportunidades, embajador), juez de la Corte Interamericana de DDHH, etc.

9 Cabe destacar que Gros Espiell se preocupa por conceptualizar el uso del término 'ciclo' como "período de tiempo" o "lapso en el que, en términos generales, existe una analogía sustancial de las formular constitucionales adoptadas en ese momento en Iberoamérica, como resultado de la acción de causas históricas y políticas similares, de la existencia de realidades y problemas comunes, aunque nunca exactamente, de las mismas influencias ideológicas o doctrinarias y de la consideración de las fuentes constitucionales predominantes en la época."; cfr. Gros Espiell, 1998:. 516. 
mismas oligarquías económicas y sociales dominantes se mantuvieron en su situación de preeminencia y privilegio" (Gros Espiell, 1998: 517-520). Si bien fueron textos irrealistas en su vigencia, Gros considera que tuvieron un importante "efecto docente".

Segundo ciclo: 1850-1870.- Hay una creciente incidencia de las ideas liberales, comienzo del debilitamiento del confesionalismo católico y laicización del Estado. Se mantiene y consolida el predominio del presidente-caudillo, y aparece la codificación autónoma de la esfera privada.

Tercer ciclo: 1870-1917. Se consolida la emancipación (liberación de Cuba), el republicanismo (fin de las últimas experiencias imperiales en México y en Brasil) y las intervenciones europeas en América Latina, aunque se abren las puertas para el intervencionismo norteamericano. Se generaliza el calificativo "democrático" para nuestras repúblicas. Comienzan los ensayos originales: derechos sociales y amparo en México, ejecutivo colegiado y autonomías en Uruguay; etc.

Cuarto ciclo: 1930-1950. Se extiende la declaración de derechos económicos, sociales y culturales, pero aparecen instituciones provenientes de la crítica anti-liberal y autoritaria del fascismo europeo, con las experiencias de Estado Novo brasileño, el peronismo argentino, y en algunos casos nuevas formas de representación corporativa al lado de los parlamentos. Aparecen primeras manifestaciones de control de constitucionalidad sobre la base del modelo norteamericano. Se mantiene el modelo de presidencialismo concentrado.

Quinto ciclo: 1954. Signada por la presencia del comunismo, las primeras experiencias anti-imperialistas y cuestionadoras del orden establecido (Guatemala, 1954; Cuba, 1959; Sandinismo en Nicaragua). La soberanía estatal cede ante las estrategias regionales para enfrentar "la amenaza comunista".

Sexto ciclo: 1980-1998. Se abre con la decadencia y desaparición de los regímenes militares en el Cono Sur. Las constituciones reflejan el retorno a textos anteriores, el dictado de nuevos, y aún la premanencia de vestigios del período autoritario. Pero hay una general revalorización conceptual y política de la democracia. Se fortalece la vida interna de los partidos, y aparecen formas más robustas de control de constitucionalidad. Sin embargo, también crece la tendencia a la reelección. A las constituciones ingresa el derecho internacional y la integración económica. 
Como puede apreciarse, dada la fecha del trabajo, no alcanza a considerar el constitucionalismo bolivariano, que irrumpe en 1999 con la reforma constitucional venezolana.

\subsection{Ciclos del constitucionalismo latinoamericano según Gargarella.}

Gargarella también adopta una periodización para abordar su estudio de 200 años de constitucionalismo latinoamericano. Para ello divide los períodos constitucionales en cinco partes:

I. Primer constitucionalismo latinoamericano (1810-1850);

II. Constitucionalismo de fusión (1850-1890);

III. Crisis del modelo de constitucionalismo poscolonial (1890-finales del siglo XIX);

IV. Constitucionalismo social (1930-mediados del Siglo XX);

V. Nuevo constitucionalismo latinoamericano (finales del Siglo XX en adelante).

\section{EL PROGRAMA DE INVESTIGACIÓN DE NEGRETTO ${ }^{10}$}

\subsection{Introducción.}

En su libro Making Constitutions ${ }^{11}$ Negretto da cuenta de una importante línea de investigación desarrollada en el marco de sus estudios de doctorado en los EEUU. En lo que sigue haremos una reconstrucción de su programa de investigación.

\subsection{Objetivos}

El autor sostiene que "los politólogos consideran las constituciones y sus distintos diseños constituyen variables cruciales para explicar resultados políticos, y económicos relevantes, como la estabilidad y la calidad de la democracia, el crecimiento económico o la frecuencia de los cambios en política pública." Hay pocos estudios que traten de explicar el origen y el cambio de los diseños constitucionales desde una perspectiva comparada. Es decir, la idea es pasar de estudios donde las constituciones son la variable independiente a aquellos en que la constitución, o más específicamente el diseño constitucional es la variable dependiente.

10 Negretto (Buenos Aires, 1962) es abogado (UBA) y cientista político por la Univ. de Columbia. Es docente e investigador en México (CIDE) y en los Estados Unidos (universidades de Columbia, Princeton, Notre Dame, etc.)

11 Negretto, Gabriel. Making Constitutions: Presidents, Parties and Institutional Choice in Latin America. Nueva York: Cambridge University Press, 2013. En el texto las referencias son a la traducción española: Negretto, Gabriel, La política del cambio constitucional en América Latina, México, FCE, CIDE, 2015. 
Por lo cual plantea "una perspectiva que busca entender el origen de los diseños constitucionales, la pregunta central es por que quienes elaboran una constitución en un momento dado eligen un conjunto particular de instituciones y no otro.” (Negretto, 2013: 19).

\subsection{Objeto}

Negretto va a estudiar el "cambio constitucional" como "punto de partida para abordar el problema general del cambio en las instituciones políticas formales."

a) cambio constitucional, mirado formalmente.

Negretto se interesará por lo que denomina 'cambio constitucional', y no por las constituciones miradas estáticamente, como suele hacerlo la dogmática.

En tal sentido, aclara que las constituciones pueden alterarse por diversos medios:

(i) alteraciones textuales, ya sea en forma de enmiendas o de un remplazo total.

(ii) sin cambios textuales, en general mediante la interpretación de una corte constitucional.

(iii)) por medio de decisiones legislativas y ejecutivas,

(iv) a través de prácticas informales de los actores politicos.

Negretto circunscribe su estudio a la modalidad (i) (remplazos y enmiendas constitucionales) por dos razones:

Primero, porque "son las únicas formas de transformación constitucional que pueden observarse de manera directa y compararse en un número de casos relativamente alto" (Negretto, 2013: 25).

Segundo, porque si bien

"las reglas formales [son] relevantes en cualquier sistema constitucional [pero] su importancia tiende a ser aún mayor en contextos donde las constituciones tienen corta vida. En un sistema constitucional maduro y de larga duración, las reglas formales que integran la constitución tienden a convertirse en secundarias, tanto para entender su funcionamiento real como para detectar los cambios que experimenta a través del tiempo. A medida que un sistema constitucional se consolida, las constituciones se transforman menos por cambios textuales que por medio de tradiciones, interpretaciones y prácticas constitucionales establecidas. En cambio, allí donde la constitución formal tiende a cambiar frecuentemente, sea por remplazos o por revisiones profundas a su texto, no hay tiempo de desarrollar interpretaciones o prácticas aceptadas de la misma. Es por esta razón que en contextos de inestabilidad constitucional la lucha por definir los limites y alcances del ejercicio del poder se canaliza frecuentemente en reformas al texto de la constitución. Como los actores políticos no confían en que las reglas formales perduren, ponen un mayor esfuerzo en definir todos los detalles posibles del uso del 


\section{LA INVESTIGACION HISTORICO-COMPARATIVA DEL CONSTITUCIONALISMO \\ LATINOAMERICANO Y EL CASO URUGUAYO}

poder por medio de reglas formales. En otras palabras, el formalismo es en gran medida, y quizás irónicamente, un fenómeno derivado de la inestabilidad institucional". (Negretto, 2013: 18)

Estas consideraciones justifican -a juicio de Negretto- la elección del objeto de investigación para el contexto latinoamericano, caracterizado -precisamente- por la debilidad democrática e institucional.

b) alcance de la naturaleza del cambio: remplazos y enmiendas.

Es importante consignar cómo entiende Negretto los cambios constitucionales, y la distinción entre remplazos y enmiendas. Al respecto señala:

(i) significación jurídica: "mientras los remplazos implican la ruptura de la legalidad constitucional, las enmiendas preservan la continuidad de la constitución existente (Negretto, 2013: 36).

(ii) en cuanto al órgano que las produce: "Las nuevas constituciones suelen ser adoptadas por una asamblea constituyente elegida por el pueblo, mientras que las enmiendas tienden a ser sancionadas por asambleas legislativas ordinarias que operan de acuerdo con procedimientos especiales."

(iii) significación jurídico-política: “el reemplazo de una constitución es el episodio más significativo de cambio constitucional. Sancionar una nueva constitución implica activar el poder constituyente del pueblo, el cual interrumpe la vida de la constitución existente y conduce, en la práctica, a su derogación. Por esta razón, el frecuente remplazo de las constituciones puede poner en entredicho los fundamentos legales del regimen político y la autoridad de la carta magna en tanto ley suprema." Para Negretto, la sanción de una nueva constitución tiene un carácter "disruptivo".

(iv) profundidad del cambio: "Las nuevas constituciones (...) casi siempre originan innovaciones institucionales importantes" o sea, sirven para "introducir alteraciones en la estructura basica del Estado", mientras que las enmiendas "suelen ser adecuadas para revisar detalles de procedimiento o cuestiones de politica legislativa contenidas en las clausulas constitucionales". Por tal motivo, los reemplazos deberían ser excepcionales

(v) en términos histórico-políticos, Negretto señala que "Supuestamente, las constituciones se establecen mediante la decisión soberana del pueblo, y ella debería ocurrir solo en momentos extraordinarios, como en una revolución o en medio de una crisis política importante. La

Rev. Brasileira de Teoria Constitucional | e-ISSN: 2525-961X| Maranhão | v. 3 | n. 2 | p. 94 - 122 | Jul/Dez. 2017 
creación de nuevas constituciones en el contexto de democracias establecidas y de larga duración parece confirmar este supuesto", como en los casos de Estados Unidos y otros países europeos como Noruega, los Países Bajos y Bélgica, que conservan constituciones sancionadas en el siglo XIX.

(vi) Negretto consigna esta distinción: "Para los efectos de este análisis, una constitución se considera como nueva cuando, sin importar el procedimiento que se haya seguido para su adopción, sus redactores la presentaron como tal habitualmente mencionando al final de su texto que se abroga la constitución previa y todas sus enmiendas. En casos dudosos consulté fuentes locales, y cuando éstas diferían, identifiqué como constituciones nuevas aquéllas que fueron sancionadas por una asamblea especialmente elegida para redactar una constitución. Las constituciones que fueron reinstauradas luego de ser abrogadas también se consideraron como nuevas." (Negretto, 2013: 37, n.14).

Al fin de cuentas, el alcance de su objeto incluye los remplazos y las enmiendas, sólo cuando tengan relevancia y no se trate de modificaciones meramente técnicas.

\subsection{Diseño: problema, teorías, estrategias metodológicas y variables.}

\section{a) Problema.}

Para Negretto el problema de investigación refiere a cuáles son los factores que determinan las elecciones de diseño constitucional, teniendo como foco las reglas electorales y las de toma de decisiones.

\section{b) Marco teórico}

Las teorías que revisa y luego coteja empíricamente son las siguientes:

En primer lugar, el autor hace consideraciones sobre los análisis del institucionalismo histórico y de las teorías de la elección racional, donde elogia especialmente a estas últimas.

En segundo término, coteja empíricamente las teorías cooperativas de los economistas, las distributivas de los politólogos, las que enfatizan el legado histórico, la difusión, el pluralismo social y las condiciones económicas.

Las teorías cooperativas y distributivas atribuyen los orígenes del diseño constitucional a las preferencias instrumentales de los agentes. Los políticos seleccionan las mejores opciones teniendo en cuenta los resultados que esperan obtener. Unas suponen resultados cooperativos 
(Tsebelis,G., 1990) y otras suponen efectos distributivos (Buchanan, James y Tullock, G.,1962).

La teoría del legado histórico, toma en cuenta los efectos de las reglas precedentes sobre la elección constitucional. La misma busca determinar si los costos del cambio institucional obligan a mantener o cambiar sólo de manera incremental las reglas electorales o de decisión vigentes (North, D.1990).

La teoría que enfatiza la difusión o imitación supone que los reformadores eligen cierto diseño constitucional según la frecuencia con que este se ha adoptado en países que tienen una vinculación geográfica, cultural o política (Zachary Elkins y Beth Simmons, 2005; Garcé, 2017).

Las referencias al pluralismo social, usadas especialmente por los académicos que trabajan sobre sistemas electorales, ${ }^{12}$ sostienen que cuanto mayor sea el número de clivajes. sociales en un país, más incluyentes serán las reglas electorales que elijan los reformadores (Rokkan, 1970; Lijphart, 1992; Amorin Neto y Cox, 1997).

Finalmente, sobre el cotejo de las condiciones económicas (inflación y crecimiento), se argumenta que situaciones críticas del punto de vista económica pueden incidir en las reglas de reelección, en el sentido de eliminar la prohibición de reelección consecutiva del Presidente y en los poderes presidenciales, aumentando los poderes legislativos de éste (Elkins, Ginsburg y Melton, 2009).

\section{c) Estrategias metodológicas. Cuantitativa y cualitativa. Mixtas}

Este trabajo combina dos estrategias metodológicas.

La primera, de tipo cuantitativo o estadística, donde se estudian muchos casos y pocas variables, concretamente se analizan comparativamente 68 reformas constitucionales y enmiendas en 18 países latinoamericanos entre 1900 y 2008. Las observaciones seleccionadas fueron implementadas en su mayoría durante años clasificados como democráticos por analistas de regímenes democráticos. El criterio fue que los cambios constitucionales fueran sancionados por partidos civiles electos mediante voto popular desde 1900 y que estuvieron vigentes durante años en que se realizaron elecciones para Ejecutivo y Congreso en las que haya competido más de un partido independiente.

12 Aunque también los que investigan sobre regímenes de bienestar han asociado los regímenes liberales con sistemas con mayor número de clivajes. 
La segunda, de tipo cualitativo o histórica, donde se analizan pocos casos y muchas variables, concretamente cuatro casos Argentina en 1949 (cuando el Partido Peronista controlaba por completo la Asamblea Constituyente) y 1994 (cuando el mismo partido tuvo que negociar con la oposición la reelección presidencial), Colombia en 1991 (una crisis política condujo a un sistema constitucional más representativo) y Ecuador en 1998 (otra crisis llevó al fortalecimiento legal del Poder Ejecutivo). Para este análisis utiliza process tracing con el propósito de cotejar la conexión causal en los cuatro casos.

Finalmente, el Autor sostiene que su estrategia es mixta, en el sentido de que lo cualitativo se propone como estrategia complementaria al análisis cuantitativo de 68 casos, y no para verificar los hallazgos realizados en los cuantitativo, sino para ampliar la comprensión del objeto de estudio.

\section{d) Variables: dependientes e independientes (explicativas).}

La caracterización de la variable dependiente, se hace a partir del examen de dos dimensiones, las reglas electorales y las de toma de decisiones.

\begin{tabular}{|l|l|}
\hline \multicolumn{2}{|c|}{ Variables dependientes: cuatro decisiones de diseño constitucional } \\
\hline las fórmulas electorales para elegir presidente & $\begin{array}{l}\text { Grado de restricción que las reglas electorales imponen sobre el número } \\
\text { de candidatos que pueden competir con cierta probabilidad de éxito en } \\
\text { las elecciones presidenciales }\end{array}$ \\
\hline las reglas que rigen la reelección presidencial & $\begin{array}{l}\text { Grado de restricción que las reglas electorales imponen sobre la } \\
\text { capacidad legal del presidente para reelegirse. }\end{array}$ \\
\hline los poderes legislativos de los presidentes 13 & $\begin{array}{l}\text { Grado de influencia que la constitución otorga al presidente en materia } \\
\text { legislativa }\end{array}$ \\
\hline los poderes no legislativos de los presidentes & $\begin{array}{l}\text { Grado de influencia que la constitución otorga al presidente en materia } \\
\text { no-legislativa }\end{array}$ \\
\hline
\end{tabular}

13 Negretto considera que "Los poderes institucionales de que gozan los presidentes como colegisladores son de una naturaleza distinta que los poderes que poseen como jefes de gobierno o de la administración. Al respecto, su referencia es Shugart, Matthew Soberg y Carey, John M.; President and Assemblies: Constitutional Design and Electoral Dynamics, Cambridge University Press, Cambridge, Estados Unidos, 1992, cap. VIII. 


\section{LA INVESTIGACION HISTORICO-COMPARATIVA DEL CONSTITUCIONALISMO LATINOAMERICANO Y EL CASO URUGUAYO}

\begin{tabular}{|c|c|c|}
\hline \multicolumn{3}{|r|}{ Variables independientes } \\
\hline Código & Descripción & Fundamentación \\
\hline NMP & $\begin{array}{l}\text { número mínimo de partidos necesario } \\
\text { para formar una coalición capaz de } \\
\text { aprobar cambios constitucionales de } \\
\text { acuerdo con la regla de decisión }\end{array}$ & $\begin{array}{l}\text { Pone a prueba el efecto que tienen los recursos de poder y los intereses partidistas sobre la } \\
\text { elección constitucional }\end{array}$ \\
\hline DESPAR & descentralización partidaria & $\begin{array}{l}\text { como una variable dicotómica codificada con valor de uno cuando los miembros del órgano } \\
\text { reformador han sido elegidos mediante listas abiertas, flexibles o cerradas múltiples, o de } \\
\text { cero si han sido elegidos mediante listas cerradas únicas }\end{array}$ \\
\hline EDADPAR & $\begin{array}{l}\text { edad en años del partido más grande } \\
\text { dentro del órgano reformador, desde su } \\
\text { fundación hasta el momento del remplazo } \\
\text { o enmienda de una constitución }\end{array}$ & $\begin{array}{l}\text { busca determinar si la edad (y por ende el grado de institucionalización) del partido más } \\
\text { grande influye en la selección de reglas electorales y de decisión. mide la edad en años del } \\
\text { partido más grande dentro del órgano reformador, desde su fundación hasta el momento } \\
\text { del remplazo o enmienda de una constitución. Esta variable busca determinar si la edad (y } \\
\text { por ende el grado de institucionalización) del partido más grande influye en la selección } \\
\text { de reglas electorales y de decisión. }\end{array}$ \\
\hline IDEOPAR & $\begin{array}{l}\text { el posicionamiento relativo del partido } \\
\text { más grande en el espectro ideológico }\end{array}$ & $\begin{array}{l}\text { mide el posicionamiento relativo del partido más grande en el espectro ideológico. Esta } \\
\text { variable oscila entre cero, cuando la posición promedio del partido es centrista, y dos, } \\
\text { cuando tiene una clara postura de izquierda o derecha. Los partidos que combinan } \\
\text { posiciones de ambos extremos reciben un valor intermedio de uno }\end{array}$ \\
\hline LEGADO & $\begin{array}{l}\text { efecto de las reglas precedentes sobre la } \\
\text { elección constitucional. }\end{array}$ & $\begin{array}{l}\text { refleja el valor rezagado de la variable dependiente en el momento de la reforma, e intenta } \\
\text { determinar si los costos del cambio institucional obligan a los reformadores a mantener o } \\
\text { cambiar sólo de manera incremental las reglas vigentes para elegir y reelegir al Ejecutivo } \\
\text { o los poderes actuales del presidente. Para facilitar la interpretación del efecto de inercia } \\
\text { cuando la variable dependiente es ordinal (que es el caso de fórmulas de elección y reglas } \\
\text { de reelección presidencial), dividí los legados institucionales en variables dicotómicas k-1. } \\
\text { Esta medición posibilita distinguir y comparar los efectos inerciales que generan las } \\
\text { distintas reglas vigentes en el momento de la reforma. }\end{array}$ \\
\hline DIFUSIÓN & $\begin{array}{l}\text { efecto de la imitación o el contagio de } \\
\text { instituciones foráneas sobre la elección } \\
\text { constitucional. }\end{array}$ & $\begin{array}{l}\text { Esta variable rastrea el efecto del número de países que adoptan una institución particular } \\
\text { sobre la probabilidad de que otro país dentro de la misma región geográfica adopte la } \\
\text { misma institución. }\end{array}$ \\
\hline FRAGET & $\begin{array}{l}\text { variable continua que mide el nivel de } \\
\text { fragmentación étnica en el país en el } \\
\text { momento de la selección institucional. }\end{array}$ & $\begin{array}{l}\text { intenta determinar la repercusión de la heterogeneidad social sobre la selección de fórmulas } \\
\text { electorales para presidente y reglas de reelección. }\end{array}$ \\
\hline INFLACIÓN & aumento en el nivel general de precios & gravedad de las condiciones económicas en el momento de la reforma \\
\hline $\begin{array}{l}\text { CRECIMIEN } \\
\text { TO }\end{array}$ & evolución del Producto Bruto Interno & gravedad de las condiciones económicas en el momento de la reforma \\
\hline
\end{tabular}

\subsection{Resultados}

Como resultado de la combinación de estrategias adoptadas, el autor propone una teoría a dos niveles o de doble lógica en la selección de reglas constitucionales.

En primer lugar, los intereses partidistas y el poder relativo de los reformadores en el momento de diseñar constituciones son factores determinantes. $\mathrm{O}$ sea, el juego político partidario es muy relevante.

En segundo término, el grado de importancia de los factores anteriores depende del acontecimiento que da origen al proceso (crisis política que modera el efecto anterior) y el realineamiento de fuerzas electorales, donde los cálculos partidistas de corto plazo prevalecen. 


\subsection{Observaciones críticas}

A partir de este marco conceptual, nos abocamos a corroborar qué tan consistente ha sido su utilización para elaborar las series estadísticas. Allí surgen varias inconsistencias:

a) En el cuadro I.1. sobre "Cambio constitucional en América Latina” (Negretto, 2013: 38), para Argentina Negretto consigna que desde la independencia registra 4 constituciones, entre 1900 y 2008 también 4 constituciones, y entre 1978 y 2008 una constitución. Esto parece corresponderse con el criterio establecido en (f), dado que la serie constitucional argentina registra:

-constitución de 1853+

-constitución de 1949

-constitución de 1957 (restablecimiento de la de 1853 con modificaciones)

-constitución de 1994

Sin embargo, nos queda la duda de cuál es la caracterización de los estatutos revolucionarios de 1966 (golpe de estado encabezado por Onganía) y de 1976 (golpe de estado encabezado por Videla). Según el criterio (f) había nueva constitución cuando, "sin importar el procedimiento que se haya seguido para su adopción, sus redactores la presentaron como tal habitualmente mencionando al final de su texto que se abroga la constitución previa y todas sus enmiendas". De acuerdo con esto, queda la duda de cómo considerar las reformas impuestas por golpes de estado, como los estatutos de $1966^{14}$ y de 1976.

El problema es que si no se consideran esos eventos como constituciones nuevas, entonces el período sometido a los mismos pasa a sumar a los períodos de vigencia de las constituciones normales. ¿cómo puede entenderse esto?

En el caso del Uruguay los resultados son más absurdos todavía. Con el criterio de Negretto, y su interpretación histórico-política (e) resultaría que Argentina con 4 constituciones y Uruguay con 6, arrojaría una mayor estabilidad política para Argentina. Por otra parte, en la tabla I1, Uruguay aparece sin constitución vigente en el período 1978-2008, cuando son muy obvias dos cosas: (1) que alguna constitución debió haber; por lo menos (según su propio

14 En lo concerniente a nuestro tema, el Estatuto de la Revolución de 1966, dispone en su Art. 3: "El gobierno ajustará su cometido a las disposiciones de este Estatuto, a las de la Constitución nacional y leyes y decretos dictados en su consecuencia, en cuanto no se opongan a los fines enunciados en el Acta de la Revolución Argentina." 
criterio) "Las constituciones que fueron reinstauradas luego de ser abrogadas también se consideraron como nuevas.” (Negretto, 2013: 37), es obvio que en 1985 se reinstauró la constitución de 1967 (aunque con modificaciones parciales y transitorias).

b) Si consideramos ahora el cuadro III.1 (Negretto, 2013: 108) vemos que Argentina registra dos remplazos $(1949,1994)$ y ninguna enmienda, mientras que Uruguay registra 4 remplazos $(1917,1942,1952,1967)$ y 1 enmienda (1996). Para empezar, esto daría una ratio de estabilidad constitucional sorprendente para Argentina (como ya observamos) y para Uruguay todo lo contrario.

Sin embargo, para el caso de Uruguay habría que mencionar lo siguiente: (i) ateniéndonos a los criterios formales, los remplazos son más, porque omite 1934, y las enmiendas también porque omite las de 1936 y 1989. (ii) Por otra parte, el caso uruguayo desvirtúa los criterios más sustanciales, dado que a pesar de existir formalmente reemplazos, las constituciones ha mostrado continuidades muy significativas desde 1934 a la fecha, que hablarían más bien de enmiendas.

c) Si vemos ahora el cuadro A.1, observamos que para Uruguay (Negretto, 2013: 318) no da cuenta de la restauración de la constitución de 1967 operada en 1984, que según Negretto debe considerarse como un remplazo (Negretto, 2013: 37). El criterio es inconsecuente, pues para Argentina considera que la restauración de la constitución de 1853 por el golpe de 1955 vale como remplazo (Negretto, 2013: 315).

De acuerdo con esto, cabe preguntarse sobre la relevancia histórico-política de los criterios formales adoptados por el autor considerado.

\section{EL PROGRAMA DE INVESTIGACIÓN DE GARGARELLA 15}

\subsection{Introducción}

La segunda investigación que hemos elegido para analizar es la desarrollada por Roberto Gargarella (2013), quien a propósito del bicentenario del movimiento emancipatorio, publica una interpretación de doscientos años de constitucionalismo en América Latina. He aquí una reeconstrucción de su línea de investigación.

15 Gargarella (Buenos Aires, 1964 - ...) es un abogado, sociólogo, y profesor de derecho constitucional argentino. 


\subsection{Objeto}

Gargarella se propone "examinar los dos siglos de vida que lleva el constitucionalismo latinoamericano (1810 - 2010)", entendiendo el constitucionalismo "en un sentido limitado del término, reducido fundamentalmente a las reglas que organizan el poder (típicamente, a partir de la creación de las ramas de poder Ejecutivo, Legislativo y Judicial), y a la vez lo limitan, sobre todo, a partir de una lista de derechos" (Gargadella, 2013: 7-8).

Más adelante precisa que "Aunque estaré pensando, en lo que sigue, muy particularmente en Constituciones (y, en especial, en Constituciones escritas), lo cierto es que mi interés irá más allá de ellas para abarcar, también, proyectos de reforma constitucional, implementados o no, y más arriesgadamente, programas abarcativos sobre cómo organizar las bases generales de la sociedad (lo que John Rawls denominaría su “estructura básica', un concepto que incluye, pero que a la vez excede claramente, el marco de la Constitución escrita)" (Gargadella, 2013: 14).

\subsection{Objetivos}

Los propósitos del trabajo de Gargarella son variados, pero declara que fundamentalmente son tanto descriptivos como normativos.

(i) como propósito descriptivo: "la idea es examinar las principales líneas de pensamiento constitucional, desarrolladas en la región en todos estos años. Por su enfoque, el acercamiento que aquí se planea difiere del que se ha podido hacer desde otras áreas, preocupadas exclusivamente del derecho, y no de las circunstancias que lo rodean y le dan significado y sentido; o excesivamente despreocupadas del mismo, para concentrarse fundamentalmente en factores explicativos en torno a por qué se escogieron tales o cuales instituciones." (Gargadella, 2013: 9)

(ii) como propósito normativo: "pensar críticamente el constitucionalismo regional, tomando como punto de mira una idea robusta de la igualdad — reflejada en un doble compromiso con el autogobierno colectivo y la autonomía individual — que ha jugado un papel tan central en la historia legal de la región. La idea principal es que, a través de las próximas páginas, los eventuales lectores encuentren un apoyo teórico desde donde evaluar lo acontecido, y comenzar a imaginar respuestas frente a los interrogantes planteados a lo largo del texto"(Gargadella, 2013: 9).

"Todo este estudio estará recorrido, sistemáticamente, por algunas intuiciones y preocupaciones fundamentales, y un hilo conductor común. (a) La preocupación 


\section{LA INVESTIGACION HISTORICO-COMPARATIVA DEL CONSTITUCIONALISMO \\ LATINOAMERICANO Y EL CASO URUGUAYO}

básica de esta obra tiene que ver con la desigualdad, que aparece marcando a todas las esferas de la organización del poóet —social, política, económica y que, históricamente, en la región, ha afectado más a algunos grupos que a otros (mujeres, indígenas, afrodescendientes, por ejemplo). (b) La intuición principal, mientras tanto, señala que el sistema institucional tiene una responsabilidad significativa en la consolidación de ese sistema político, económico y social que sigue siendo, después de doscientos años de independencia, profundamente desigual. Buena parte del libro gira en torno de ese problema: los límites establecidos por el pasado, y las dificultades para $-\mathrm{y}$ la necesidad de sobrepasarlo. (c) El hilo común que recorre todo el libro es la indagación en torno a una manera diferente de pensar y organizar la vida democrática." (Gargadella, 2013: 11).

\subsection{Diseño: problema, teoría, estrategia metodológica y variables.}

\section{a) Problema}

En Gargarella no encontramos un planteamiento explícito del problema de su investigación, pero pensamos que fácilmente puede indentificarse como el siguiente:

¿Qué límites ha establecido el pasado institucional latinoamericano para que 200 años después de su origen, se mantengan las enormes desigualdades?(Gargadella, 2013: 11).

¿por qué a pesar de un avance significativo en la proclamación de derechos (parte dogmática) no se ha avanzado significativamente en lograr sociedades más igualitarias?

¿Por qué ese problema pervive aún en la última oleada de constituciones bolivarianas, inspiradas en el pensamiento de izquierda?

¿Cuáles son las razones para la ausencia de una fuerza que defendiera al mismo tiempo los ideales de autogobierno y autonomía individual de manera consistente? En otros términos, ¿por qué no existió una alianza radical-liberal que articulara ambos ideales, del mismo modo que se dió la alianza conservadora-liberal para articular la defensa de la concentración de poder y la autonomía individual? (Gargadella, 2013: 349).

\section{b) Marco teórico}

Gargarella apela a distintas premisas teóricas, unas veces explícitas y otras veces implícitas, que no se detiene a discutir o fundamentar, pero que guían toda su investigación. Quien estudie su obra deberá contar con esas premisas o directamente deberá poner en cuestión toda su argumentación.

Tratemos de ordenar esas premisas teóricas -hipótesis teóricas- que, ordenadamente conformarían un completo y coherente marco teórico de la investigación.

Hipótesis teóricas 
(i) "la cuestión institucional, y particularmente la que se refleja en las opciones constitucionales de una comunidad, son lo suficientemente relevantes como para hacerse acreedores de nuestra atención, en lugar de ser consideradas superficiales o meramente superestructurales." (Gargadella, 2013: 8). En sus conclusiones, Gargarella es más explícito en términos causales:

"La deficitaria situación institucional, arriba descripta, nos refiere a la importancia y necesidad de reformas constitucionales, destinadas a resolver algunas de las situaciones antes mencionadas. Por supuesto, decir esto no implica considerar que los problemas que enfrenta la región -problemas que mezclan cuestiones políticas, sociales, económicas y culturales- puedan ser resueltos, simplemente, apelando a reformas constitucionales. Lo que se dice es más bien lo opuesto, es decir, que tales problemas no pueden ser enfrentados sin recurrir, también, a cambios de tipo legal." Es decir, según su concepción, los arreglos constitucionales no son la causa, pero son condición necesaria -no suficiente- para producir cambios efectivos en términos sociales, políticos y económicos." (Gargadella, 2013: 354).

(ii) las decisiones institucionales (en especial las constitucionales) dependen de la conformación de un poder social guiado por una elite intelectual consciente de sus intereses estratégicos y capaz de conformar un acuerdo ideológico-político que posibilite y de sustento a los arreglos institucionales. En este énfasis teórico se puede reconocer una impronta que lo conecta con las teorías elitistas. 16

(iii) el desarrollo de un sistema institucional tiene una responsabilidad significativa en la consolidación posterior del sistema político, económico y social. De manera que la conformación de actual de los sistemas institucionales es dependiente de la conformación originaria y su posterior desarrollo (Gargadella, 2013: 11).

(iv) las constituciones se conforman de dos partes o zonas: la dogmática (aspiraciones) y la organización del poder (sala de máquinas). Si no se diseñan armónicamente, entran en tensión, y una puede desactivar a la otra.

(v) las decisiones constitucionales han girado en torno a dos grandes ideales, y tres concepciones respecto de los mismos:

16 Gargarella nos da una pista de ello cuando destaca que "hay mucho que aprender del constitucionalismo regional" el cual "incluye entre sus filas a cantidad de estadistas, juristas y teóricos notables: Juan Bautista Alberdi, Francisco Bilbao, Simon Bolívar, Juan Egaña, José González Vigil, Victorino Lastarria, José Carlos Mariátegui, Juan Montalvo, José María Mora, Mariano Otero, Manuel Murillo Toro, José María Samper, Domingo Sarmiento, entre tantos otros." (Gargarella, La Sala de Máquinas..., p. 8). 


\section{LA INVESTIGACION HISTORICO-COMPARATIVA DEL CONSTITUCIONALISMO LATINOAMERICANO Y EL CASO URUGUAYO}

\begin{tabular}{|c|c|c|c|}
\hline \multirow[t]{2}{*}{ Características } & \multicolumn{3}{|c|}{ Tres concepciones sobre los arreglos constitucionales } \\
\hline & Conservador & Liberal & Republicano (radicalismo) \\
\hline Matriz de origen & el Imperio español & $\begin{array}{l}\text { la Revolución } \\
\text { norteamericana }\end{array}$ & la Revolución Francesa \\
\hline${ }_{17}^{\text {Ideal de gobierno }}$ & $\begin{array}{l}\text { Elitismo político, verticalismo, concentración del poder. Visión } \\
\text { restrictiva del autogobierno. Asumio la postura mas restrictiva y } \\
\text { elitista respecto del papel de la voluntad mayoritaria, en el } \\
\text { control de la vida política de la comunidad. (Gargarella, op. } \\
\text { cit. p. } 348 \text { ) }\end{array}$ & $\begin{array}{l}\text { Autogobierno colectivo } \\
\text { (mayoritarismo) y autonomía } \\
\text { individual,(libertad), } \\
\text { priorizando este segundo } \\
\text { ideal. }\end{array}$ & $\begin{array}{l}\text { Autogobierno } \begin{array}{r}\text { colectivo } \\
\text { (mayoritarismo) y autonomía }\end{array} \\
\text { individual (libertad), aunque } \\
\text { postergando el segundo, en } \\
\text { favor del bienestar general. }\end{array}$ \\
\hline $\begin{array}{l}\text { Ideal moral } \\
\text { individual }^{18}\end{array}$ & $\begin{array}{l}\text { Perfeccionismo moral, valores supraindividuales y } \\
\text { extracomunitarios. Opuesto a la autonomía individual. El } \\
\text { sistema constitucional debía estar al servicio de una particular } \\
\text { concepción del bien, en particular la religión católica. Defendió } \\
\text { la asociación del Estado y la Iglesia. }\end{array}$ & $\begin{array}{l}\text { Autonomía individual como } \\
\text { centro: el orden } \\
\text { constitucional debe servir a } \\
\text { la idea del respeto a las libres } \\
\text { elecciones individuales. }\end{array}$ & $\begin{array}{l}\text { Autonomía individual, pero } \\
\text { sujeta a su compromiso } \\
\text { fundamental con el ideal del } \\
\text { autogobierno. }\end{array}$ \\
\hline $\begin{array}{l}\text { Actitud post- } \\
\text { revolucionaria }\end{array}$ & $\begin{array}{l}\text { Impulsó una alianza estratégica con los liberales, mediante } \\
\text { arreglos constitucionales para (a) defender la organización } \\
\text { económica existente, y en especial, el derecho de propiedad; (b) } \\
\text { evitar las amenazas del proyecto mayoritario de sus adversarios } \\
\text { y su discurso radical-democrático. }\end{array}$ & $\begin{array}{l}\text { Aceptó la alianza con la elite } \\
\text { conservadora. }\end{array}$ & \\
\hline $\begin{array}{l}\text { Constitucio- } \\
\text { nalismo del S. XIX }\end{array}$ & $\begin{array}{l}\text { Hiperpresidencialismo. Orden y progreso. Libertades políticas } \\
\text { restringidas y libertades civiles (económicas) amplias (Alberdi) }\end{array}$ & $\begin{array}{l}\text { Asegurameniento de la } \\
\text { propiedad privada; derechos } \\
\text { de libertad individual. }\end{array}$ & $\begin{array}{l}\text { Servicios públicos; derechos de } \\
\text { participación }\end{array}$ \\
\hline $\begin{array}{l}\text { Constitucio- } \\
\text { nalismo S. XX }{ }^{19}\end{array}$ & $\begin{array}{l}\mathrm{Su} \text { habilidad, logra frustrar todos los intentos liberales y } \\
\text { republicanos, manteniendo el control de la "sala de máquinas" } \\
\text { constitucional. }\end{array}$ & $\begin{array}{l}\text { Frustración sistemática del } \\
\text { ideal libertario }\end{array}$ & $\begin{array}{l}\text { Frustración sistemática de la } \\
\text { transformación igualitaria de la } \\
\text { sociedad }\end{array}$ \\
\hline $\begin{array}{l}\text { Segunda oleada } \\
\text { reformista (fines } \\
\text { del S. XX) }\end{array}$ & $\begin{array}{l}\text { Su legado institucional (concentración del poder) no resulta } \\
\text { afectado por el constitucionalismo bolivariano, pero empieza a } \\
\text { deteriorarse por reformas minimalistas en acceso a la justicia, } \\
\text { participación, etc. }\end{array}$ & $\begin{array}{l}\text { Impulsa reformas } \\
\text { minimalistas en la "sala de } \\
\text { máquinas" que resultan en } \\
\text { avances para la autonomía } \\
\text { individual y el autogobierno }\end{array}$ & $\begin{array}{l}\text { Avances en demandas e } \\
\text { inclusión de grupos sociales } \\
\text { postergados: grupos indígenas, } \\
\text { consumidores, minorías de } \\
\text { género y culturales. }\end{array}$ \\
\hline
\end{tabular}

c) Estrategia metodológica.

17 En este punto, los ideales en tensión son el aristocratismo y el autogobierno. El primero considera que una minoría tiene más derecho a gobernar, mientras que el ideal del autogobierno defiende el igual derecho de todos a decidir sobre los destinos de la vida colectiva (Gargarella, 2013: 348).

18 Opuesto al perfeccionismo moral que venía impuesto desde el centro del dominio Colonial. (Gargarella, 2013: 348)

19 Dice Gargarella: "Desde el comienzo del siglo XX (...) Las viejas Constituciones fueron reformadas, en un intento de reflejar las nuevas condiciones sociales que habían aparecido en la región. El objetivo era presentar, a través de estos documentos legales, una síntesis perfecta de las demandas de liberales, conservadores y radicales. Alguno podría sugerir, entonces, que la región había decidido pasar del pacto liberal-conservador a un nuevo pacto, el ecuménico acuerdo liberal-conservador-radical." (Gargarella, 2013: 352). "Sin embargo, contra dicha visión, señalamos en las páginas anteriores algunos problemas serios que afectaron y pusieron en cuestión a dicha empresa. Por un lado, la operación constitucional de "alianza completa" que comenzara a implementarse desde el siglo XX no honraba en definitiva los ideales tradicionales, básicos, del radicalismo (que, conforme señaláramos, resultaban desvirtuados tanto en relación con su aproximación a la organización del poder, como en relación con su modo de responder a la "cuestión social"). Por otro lado, y en relación con el punto anterior, la "incorporación" del radicalismo se hacía de un modo muy problemático, en términos de diseño constitucional. Para decirlo brevemente, se reservaba para la vieja alianza liberal-conservadora el control de la "sala de máquinas" de la Constitución, mientras que se delegaba a los grupos más radicales el trabajo sobre la sección de los derechos. El resultado de esta distribución de tareas fue el crecimiento de Constituciones en fuerte tensión interna (en donde una parte de la Constitución se constitúa en principal amenaza de la otra), y el mantenimiento de una estructura de poder todavía muy impermeable a las crecientes demandas sociales provenientes desde la sociedad civil -lo que aseguraba el surgimiento de más tensiones entre ciudadanía y Constitución-." (Gargarella, 2013: 352-353). 
Gargarella adopta un diseño cualitativo. Él parte de interpretaciones y busca elaborar una interpretación más refinada, más adecuada a las evidencias también interpretativas. Es lo que podríamos enmarcar una investigación hermenéutica.

Sus referencias son los testimonios de actores privilegiados, exponentes de las distintas vertientes del constitucionalismo a través de los diferentes períodos estudiados.

\section{d) Variables}

Si el programa de investigación de Gargarella no pretende ser una investigación empírica explicativa (al menos en esta etapa) es obvio que no podemos hablar de variables analíticamente definidas. No obstante, a los fines comparativos que nos proponemos -entre los programas de Negretto y Gargarella- será útil manejar la idea de variables determinantes y dependientes, en términos hermenéuticos, de un modo análogo a como funcionarían en un diseño explicativo.

Esto es posible, a nuestro juicio, porque los abordajes hermenéuticos pueden perfectamente preparar el camino para investigaciones más rigurosas de tipo explicativo. Por otra parte, es claro que el autor deja traslucir ciertas hipótesis con fuerza explicativa.

Gargarella tiene en mente -al menos- dos tipos de causalidades: (a) la que determina las decisiones constitucionales, y (b) la causalidad de la técnica de diseño utilizada para que las constituciones cumplan efectivamente con los propósitos de sus redactores (Gargarella, 2010: 356 y ss.).

\subsection{Resultados}

Gargarella cree corroborar su hipótesis interpretativa, en dos ámbitos.

(i) en general, mirando los 200 años de republicanismo en América Latina, observa que no se ha logrado avanzar significativamente en igualitarismo ${ }^{20}$, cuando las instituciones republicanas deberían de haber producido un fuerte avance en tal sentido. Al respecto, argumenta que ello se explicaría por las circunstancias de la variable independiente (condiciones de partida): (a) la falta de capacidad política del radicalismo para gestar una alianza con sectores liberales; (b) una mayor autoconciencia de la línea conservadora acerca de sus intereses institucionales; (c) una mayor capacidad técnica para diseñar las constituciones y en última instancia, diseñar la "sala de máquinas" de las constituciones.

20 Suponemos que tiene presente la afirmación de que AL es el continente más desigual del planeta según entre otros- el índice GINI.

Rev. Brasileira de Teoria Constitucional | e-ISSN: 2525-961X| Maranhão | v. 3 | n. 2 | p. 94 - 122 | Jul/Dez. 2017 


\section{LA INVESTIGACION HISTORICO-COMPARATIVA DEL CONSTITUCIONALISMO LATINOAMERICANO Y EL CASO URUGUAYO}

(ii) una segunda línea de corroboración refiere al constitucionalismo bolivariano. A su respecto, señala que si bien la línea radical concretó alianzas capaces de ganar el apoyo político democrático, no ha sido capaz técnicamente de lograr diseños constitucionales que posibiliten alcanzar o volver sustentables sus aspiraciones. Así, a pesar de haber consagrado muchos derechos largamente ignorados, no ha logrado romper con las estructuras de poder tradicionales, y puede ello determinar a la postre un retroceso.

Respecto del constitucionalismo bolivariano ${ }^{21}$, Gargarella afirma que sus ejemplos "nos hablan de lo importante y - a la vez - de lo limitada que ha sido la tarea de quienes trabajaron en los recientes procesos de reforma constitucional: ellos no han podido o no han querido llegar tan lejos como era quizás necesario para asegurarle a tales reformas la potencia transformadora que se pretendía que tuvieran" (Gargadella, 2013: 332).

Los reformadores, "al concentrar su esfuerzo en el área de los derechos, los reformistas sociales prácticamente dejaron de lado un necesario trabajo sobre el área de la organización del poder” y “tendieron a dejar intocada la 'sala de máquinas' de la Constitución, esto es, el área de la Constitución en la que se define cómo va a ser el proceso de toma de decisiones democrático".

En cambio, "los arquitectos del pacto liberal-conservador no dudaron acerca de lo que era necesario hacer para asegurar la vigencia de sus derechos más preciados: básicamente, el derecho de propiedad implicaba, ante todo, introducir importantes modificaciones dentro de la sala de máquinas de la constitución” como era "típicamente la restricción de libertades políticas con el fin de asegurar el disfrute de libertades económicas más amplias"(Gargadella, 2013: 333). Por ejemplo, para Alberdi, se trataba de "atar las manos de la mayoría, limitar sus capacidades de actuar en política, para poder asegurar la protección de ciertos derechos económicos básicos” (Gargadella, 2013: 333).

Finalmente, Gargarella destaca la honestidad del constitucionalista argentino A.E. Sampay, quien reconoció autocríticamente el 'error' cometido cuando se quiso impulsar la reforma social, con la ayuda de la constitución, pero sin ingresar efectivamente en la 'sala de máquinas' de la misma”, en la constitución peronista de 1949 (Gargadella, 2013: 334).

21 Llamamos "bolivariano" al conjunto de reformas constitucionales promovidas a partir de la impulsada por Hugo Chávez en Venezuela (1999), y que abarca las reformas de Ecuador y Bolivia. 


\subsection{Observaciones críticas}

a) Para Gargarella hay un concepto clave: la "sala de máquinas" de las constituciones. A su juicio, ésta es la parte decisiva para la efectivización (o frustración) de las declaraciones de derechos contenidas en las constituciones. No obstante ser un concepto central, al punto de dar título al libro, Gargarella no nos brinda una definición analítica de lo que entiende por "sala de máquinas". Encontramos algunas caracterizaciones muy generales como "organización del poder" (Gargadella, 2013: 59 y ss., 245 y ss.); el "hiperpresidencialismo" (Gargadella, 2013: 272, 310 y ss.); los “controles mutuos” (Gargadella, 2013: 116 y ss., 293 y ss., 311 passim); las “instituciones participativas” (Gargadella, 2013: 311, 330 passim)”, entre otros.

A nuestro modo de ver, sería deseable que se definieran de modo más analítico el concepto de "sala de máquinas", delimitando sus contornos y componentes.

b) poca relevancia para la experiencia batllista. Las consideraciones generales sobre AL no dan cuenta adecuada del caso uruguayo.

\section{CONTRASTACIÓN DE ALGUNAS HIPÓTESIS PARA EL CASO URUGUAYO}

En este apartado buscaremos corroborar la consistencia empírica de algunas hipótesis tomadas en cuenta por los programas de investigación analizados anteriormente. A esos efectos, hemos optado por utilizar las hipótesis de Negretto, descartando el cotejo de las hipótesis implícitas en el trabajo de Gargarella. La razón de esta elección refiere únicamente a que las hipótesis de Negretto tienen un nivel de desarrollo analítico mayor, que posibilita utilizarlas con más seguridad. En el caso de Gargarella, se trata de hipótesis formuladas de manera más imprecisa y su operacionalización demandaría todavía un proceso adicional.

Nos aplicaremos a los dos casos ocurridos en los últimos 50 años de vida política en Uruguay: la reforma constitucional de 1967 y la enmienda constitucional de 1997.

A esos efectos, luego de seleccionar estos dos casos, nos focalizamos en el análisis a dos variables dependientes: las reglas de elección y las reglas de re-elección del Presidente. Por último, cotejaremos cinco variables independientes en el caso de las reglas de elección del Presidente y siete en el caso de re-elección. ${ }^{22}$

22 Los valores asignados a las variables dependientes seleccionadas a los efectos de este análisis (regla de elección del presidente y regla de reelección del presidente) fueron tomadas de la base de datos elaborada por Gabriel Negretto. Por otra parte, con respecto a las variables independientes, hemos procurado ajustarnos a 


\section{LA INVESTIGACION HISTORICO-COMPARATIVA DEL CONSTITUCIONALISMO LATINOAMERICANO Y EL CASO URUGUAYO}

En este análisis seguimos la orientación metodológica de J. S. Mill para el análisis comparado, elaborada hace más de un siglo, con los métodos de la diferencia para el primer análisis y del acuerdo para el segundo (Ver Anexo).

En primer lugar, abordamos el caso del análisis que tiene como foco la regla de elección del Presidente, hemos considerado a estos efectos el tamaño de la coalición, la edad del partido, el legado histórico, la difusión y la diversidad étnica. Para estos dos casos la variable dependiente asume dos valores, un valor de no modificación de la regla de mayoría simple en el reemplazo de 1967 y un valor de modificación en la enmienda constituticional de 1997, cuando se pasa de la regla de mayoría simple a la mayoría absoluta para elegir al Presidente.

Las variables independientes "edad del partido", "legado histórico", "difusión" y "diversidad étnica" tienen iguales valores para las dos instancias de cambio constitucional (1967 y 1997). Los partidos involucrados en la acción reformista tenían una larga vida institucional de más de un siglo, en las tres últimas constituciones la regla electoral de "elección del Presidente" tiene el mismo valor, lo que constituye un importante legado histórico, y hay un porcentaje muy relevante de los países de la región que tenían en sus constituciones la característica de la regla electoral que se mantiene o bien se modifica en las dos instancias en análisis. La única variable independiente que tiene diferente valor es "tamaño de la coalición de los partidos que aprueban la reforma", por lo que se convierte en la variable decisiva del punto de vista explicativo.

En 1967, se puede hablar de dos grandes partidos (Partido Colorado y Partido Nacional) con aproximadamente el $90 \%$ de apoyo electoral que promovieron y aprobaron la reforma y en 1997, el escenario estaba dividido entre más de tres partidos políticos, además del Partido Colorado y el Partido Nacional, el Frente Amplio que contaban cada uno con aproximadamente un tercio del apoyo parlamentario, estaba el Partido Nuevo Espacio, que tenia también aproximadamente el $5 \%$ del apoyo parlamentario, lo que configura un distribución de fuerzas políticas ligeramente diferente entre los dos momentos de cambio institucional. ${ }^{23}$

Asimismo, debe anotarse que el contexto histórico era de incertidumbre, lo cual, confirmando el argumento cooperativo de una de las lógicas de Negretto, permite fortalecer la explicación de un cambio hacia una regla electoral más inclusiva (balotaje).

los criterios propuestos por Negretto, pero con una elaboración propia, que en el caso de las variables económicas tuvo como fuente, datos del Banco Mundial y no del FMI.

23 Dejamos constancia que, siguiendo el criterio de Negretto, a los efectos de este análisis no hemos considerado las dos variables económicas (inflación y crecimiento). 
En segundo término, en el caso del análisis que tiene como foco la regla de la re-elección del Presidente, hemos considerado además de las cinco variables independientes iniciales (el tamaño de la coalición, la edad del partido, el legado histórico, la difusión y la diversidad étnica) las variables económicas de la inflación y del crecimiento económico. Para estos dos casos la variable dependiente asume el mismo valor de no modificación de la regla de la re-elección.

Las variables independientes "edad del partido", "legado histórico", de la "difusión” y de la "diversidad étnica tiene iguales valores para las dos instancias de cambio constitucional. Los partidos reformistas tiene una larga vida institucional, el legado histórico y la difusión son muy relevantes, el valor de la diversidad es igualmente homogéneo en ambos casos. Tanto el tamaño de la coalición reformista como la situación económica son diferentes. Como advertimos anteriormente el escenario que muestra las relaciones de fuerzas entre los actores politicos reformistas es senciblemente diferente, asimismo la situación económica también es marcadamente diferente, mientras que en 1967, podemos hablar de una inflación creciente y un estancamiento en el crecimiento, en 1997 la inflación era descendente y el crecimiento económico tenia una tendencia de ascenso.

En síntesis, la modificación constitucional en 1997 de la regla de elección del Presidente, se explica por razones exclusivamente políticas o de competencia política, lo que reafirma la importancia de las teorías distributivistas, sin perjuicio de que también juega la cooperación. Por otro lado, la continuidad en la regla de la re-elección del Presidente entre 1967 y 1997 , puede explicarse por la edad del partido, el legado histórico, la difusión y la diversidad étnica.

Por lo anterior, podemos afirmar que la teoría de Negretto sobre el cambio constitucional:

a) se confirma para los dos eventos de cambio constitucional en Uruguay de 1967 y 1997 , donde se cambia la regla de elección del Presidente.

b) no se confirma en los mismos dos eventos en el caso de continuidad de la regla de reelección del Presidente.

c) A diferencia de la teoría de Negretto, importa tomar en consideración las teorías del legado histórico, de la difusión y de la diversidad étnica, las que tendrian confirmación para el caso de la explicación del no cambio de la regla de re-elección del Presidente. 


\section{AGENDA DE INVESTIGACIÓN SOBRE CONSTITUCIONALISMO}

La constitución como variable dependiente:

1. Incorporar el argumento de Negretto a una teoría de mayor alcance que permita explicar el contenido de las Constituciones adoptadas en regímenes autoritarios en América Latina, por ejemplo por Comisiones especiales en regímenes militares. Esto supone aumentar el número de casos y llevaría seguramente a reformular la teoría.

2. Hacer viajar la teoría de Negretto a otras partes del mundo, por ejemplo a Europa. Esto llevaría a aumentar el número de casos y obligaría a reformular la variable dependiente, muy asociada a las reglas electorales y a las de toma de decisiones del régimen presidencialista en América Latina.

3. Realizar estudios comparados con las hipótesis teóricas de Negretto y Gargarella que involucren los casos que realizaron y los que no realizaron reformas constitucionales en el contexto reciente de nuevo constitucionalismo en América Latina.

4. Cotejar empíricamente otros casos nacionales de América Latina con las hipótesis teóricas de Negretto y Gargarella.

5. Cotejar empíricamente el crecimiento de la parte dogmática de las nuevas constituciones en América Latina y el mantenimiento de la concentración de poder en la parte orgánica de las mismas constituciones, buscando confirmar o no las hipótesis propuestas por Gargarella.

6. Desarrollar estudios cualitativos, con uno o pocos casos donde además de considerar las normas formales como variable dependiente, se consideren las prácticas (reglas informales). ${ }^{24}$

La constitución como variable independiente:

1. continuar con los estudios constitucionalistas que analizan el impacto sobre el funcionamiento del sistema político;

2. el impacto de la elaboración de constituciones en las transiciones democráticas;

3. el impacto de la elaboración de constituciones en las motivaciones individuales y los mecanismos de decisión colectiva en los procesos de cambio constitucional;

24 A estos efectos, conviene tomar en cuenta el trabajo de Levinsky sobre reglas informales. 
4. la relación entre el proceso constituyente y la legitimidad democrática;

5. el cambio constitucional como explicación de los orígenes de ciertas instituciones políticas básicas;

6. explicar el papel de las constituciones y los diseños en los resultados económicos.

\section{CONCLUSIONES}

En primer término, nos interesa dejar constancia de en que se parecen y en que se diferencian los programas de investigación de Gargarella y Negretto.

Se parecen:

a) Ambos proyectos tienen un mismo objeto: el constitucionalismo, en sus diferentes dimensiones.

b) Ambos proyectos son miradas externas al derecho, pero que toman en cuenta las acumulaciones de conocimiento en particular de los juristas.

c) Desarrollan una mirada en la frontera del derecho constitucional y la ciencia política.

Se diferencian:

a) Los objetivos de Gargarella son descriptivos y normativos, también podríamos decir interpretativos, mientras que los objetivos de Negretto son explicativos.

b) Gargarella tiene un diálogo más intenso con el mundo de la dogmática jurídica.

En segundo lugar, en este artículo, nos hemos desplazado de las teorías explicativas cuantitativas, cualitativas, mixtas o interpretativas al análisis comparado cualitativo.

El examen del caso uruguayo, de forma comparada, en dos eventos de cambio constitucional (remplazo de 1967 y enmienda de 1997) resulta confirmatorio parcialmente de los énfasis de la teoría de dos niveles de Negretto, en uno de los dos focos de análisis, la regla de elección del Presidente.

Sin embargo, en el caso de la reelección confirma las teorías alternativas del legado histórico de la difusión y de la diversidad cultural, que no habían sido confirmadas en los análisis de Negretto.

Rev. Brasileira de Teoria Constitucional | e-ISSN: 2525-961X| Maranhão | v. 3 | n. 2 | p. 94 - 122 | Jul/Dez. 2017 
En tercer término, hemos sugerido una agenda de investigación para el futuro que puede y debería tomar los siguientes lineamientos:

a) La constitución podría ser investigada tanto como variable dependiente como variable independiente.

b) Las estrategias de investigación podrían ser tanto cuantitativas, como cualitativas, o mixtas.

c) Podrían redefinirse los contenidos del diseño constitucional como variable dependiente, tomando debida cuenta de las reglas que informan a otros sistemas políticos a ser considerados en el análisis.

d) Podrían ponerse a consideración hipótesis derivadas de otras teorías, como por ejemplo, los énfasis en las reglas informales.

\section{ANEXO}

Método de la diferencia y del acuerdo de John Stuart Mill

En el método de la diferencia, los valores de la variable dependiente no son los mismos para todos los casos, y el método asume que si los resultados son diferentes, es posible encontrar una diferencia crucial entre los casos (valores diferentes para la misma variable independiente, esto es, una causa) que explica la diferencia en el resultado.

En el método del acuerdo, al contrario, cuando se encuentran resultados idénticos entre los casos estudiados (los mismos valores para la variable dependiente) se busca la identificación de regularidades o de una semejanza crucial entre los casos. 
José Miguel Busquets \& Oscar Sarlo

\section{BIBLIOGRAFIA}

Barnes, J., The Cambridge Companion to Aristotle. Cambridge, UK: Cambridge University Press, 1995.

Blaustein, Albert y Flanz, Gisbert, Constitutions of the countries of the word. Editorial Dobbs Ferry, Oceana, 1971.

Buchanan, James y Tullock, Gordon. El calculus of consent. University Michigan Press. 1962

Buquet, Daniel. Reforma política y gobernabilidad democrática en Uruguay: la reforma constitucional de 1996. Revista Uruguaya de Ciencia Política.10/1997-98.

Cordeiro, José Luis, Constitutions around the World: A View from Latin America, IDE Discussion Paper. No. 164. 2008, http://hdl.handle.net/2344/782.

Cordeiro, José Luis. Constitution around the Word: A View from Latin America, 2008.

Elkins, Zachary, "Diffusion and the Constitutionalization of Europe". Comparative Political Studies 43(8-9): 969-999, 2010.

Elkins, Zachary, Ginsburg, Tom y Melton, James. The Endurance of National Constitutions, Cambridge University Press, Nueva York, 2009.

Elkins, Zachary, y Simmons Beth. On Waves, Clusters and Diffusion: Conceptual Framework, Annals of the American Academy of Political and Social Science 598 (2005).

Garcé, Adolfo. La historia como oportunidad teórica. La difusión y reinvención del presidencialismo en América Latina durante el siglo XIX. Mimeo.2017

Gargarellla, Roberto. La Sala de Máquinas de la Constitución. Dos siglos de constitucionalismo en América Latina (1810-2010). Buenos Aires. Katz Editores. 2013.

Gros Espiell, Héctor, Intento preliminar de una determinación de ciclos en la evolución constitucional iberoamericana, en: Gros Espiell, H. Estudios Constitucionales, Montevideo, Ingranusi, 1998, pp. 515-531.

Helmke, Gretchen; Levitsky, Steven . Informal Institutions and Democracy: Lessons from Latin America Political science; JHU Press, 2006

Lijphart, Arend. Democratization and Constitutional Choice in Czecho-Slovakia, Hungary and Poland 1989-91. Journal of Theoretical Politics 4,2. (1992).

Loewenstein, Karl, Teoría de la Constitución, Barcelona, Ariel, 1970.

Negretto, Gabriel, La política del cambio constitucional en América Latina, México, FCE, CIDE, 1915.

Negretto, Gabriel. Making Constitutions: Presidents, Parties and Institutional Choice in Latin America. Nueva York: Cambridge University Press, 2013. 


\section{LA INVESTIGACION HISTORICO-COMPARATIVA DEL CONSTITUCIONALISMO \\ LATINOAMERICANO Y EL CASO URUGUAYO}

North, Douglass. Institutions, Institutional Change and Economic Performance. Cambrige University Press. 1990.

Rokkan, Stein. Citizens, Elections, Parties: Approaches to the Comparative Study of the Process of Development, Universitetsforlaget, Oslo, 1970.

Shugart, Matthew Soberg y Carey, John M.; President and Assemblies: Constitutional Design and Electoral Dynamics, Cambridge University Press, Cambridge, Estados Unidos, 1992, cap. VIII.

Shugart, Matthew y Carey, John. President and Assemblies: Constitutional Design and Electoral Dynamics, Cambridge University Press, Cambridge, Estados Unidos, 1992, cap. VIII

Tsebelis, George. Nested Games.University of California Press. Berkeley. 1990.

Vieira Machado, Cristina y Vianna, Alexandre. Direito, Rui Barbosa e a Constituição republicana portuguesa de 1911, Fundação Casa de Rui Barbosa, 2001. 